\title{
CD105(+) cells from Wharton's jelly show in vitro and in vivo myogenic differentiative potential
}

\author{
MARIA TERESA CONCONI ${ }^{1}$, PATRIZIA BURRA ${ }^{2}$, ROSA DI LIDDO ${ }^{1}$, \\ CHIARA CALORE ${ }^{1}$, MICHELA TURETTA ${ }^{1}$, SILVIA BELLINI ${ }^{1}$, PATRIZIO BO ${ }^{3}$, \\ GASTONE G. NUSSDORFER ${ }^{4}$ and PIER PAOLO PARNIGOTTO ${ }^{1}$
}

\author{
Departments of ${ }^{1}$ Pharmaceutical Sciences, ${ }^{2}$ Surgical and Gastroenterological Sciences (Section of Gastroenterology); \\ ${ }^{3}$ Obstetrics and Gynaecology Unit, Cittadella Hospital, Padua; and ${ }^{4}$ Human Anatomy and Physiology \\ (Section of Anatomy), University of Padua, I-35121 Padua, Italy
}

Received May 5, 2006; Accepted July 18, 2006

\begin{abstract}
Embryo-derived tissues, such as umbilical cord (UC), can represent attractive sources of mesenchymal stem cells because their use is not related to any ethical issue. Abundant experimental evidence has already shown that Wharton's jelly contains cells able to differentiate in vitro into adipocytes, chondrocytes, osteocytes and neurons. Human UCs were obtained from term caesarean deliveries and processed within $24 \mathrm{~h}$. Cells derived from the Wharton's jelly expressing mesenchymal markers, such as CD105, but not KDR and CD31 antigens, have been selected by positive and negative immunoseparation. These cells were characterized by an elongated shape and a good proliferation rate. Moreover, they were, at least in part, of fetal origin, as demonstrated by the expression of Sry mRNA. The expression of Myf5 and MyoD was detected after 7 and 11 days of in vitro myogenic induction, respectively. At two weeks from cell injection in the tibialis anterior muscle, previously damaged with bupivacaine, skeletal muscle appeared completely repaired and transplanted cells were present in the muscle for two weeks and differentiated into skeletal muscle cells, as demonstrated by the co-localization of HLA 1 and sarcomeric tropomyosine antigens. These observations provide the first demonstration that CD105(+)/CD31(-)/KDR(-) cells are able not only to differentiate in vivo towards the myogenic lineage, but also to contribute to the muscle regenerative process.
\end{abstract}

\section{Introduction}

Human embryonic stem cells (ESCs) obtained from the inner mass of blastocyst are characterized by high proliferative index

Correspondence to: Professor M.T. Conconi, Department of Pharmaceutical Sciences, University of Padua, via Marzolo 5, I-35131 Padua, Italy

E-mail: mariateresa.conconi@unipd.it

Key words: mesenchymal cells, umbilical cord, CD105 (endoglin), myogenic differentiation and can give rise not only to all cell types derived from the three germ layers, but also to extraembryonic tissues, such as placenta and umbilical cord (1). Despite these attractive and promising features, their use in cell therapy for the treatment of various degenerative diseases is limited or avoided because of ethical issues arising from the destruction of human blastocyst when the inner mass is removed (2). To overcome the problems connected with the use of the ESCs, the research has been focused on adult stem cells (ASCs), which have an almost ubiquitous distribution through the body. ASCs, are able to differentiate in vitro and in vivo into various cell types not only belonging to the tissue of origin, since this process depends on environmental signals switching on the genes involved in the differentiation programs (3-5). Bone marrow represents the most employed source of hematopoietic and mesenchimal ASCs (6). Nevertheless, the use of ASCs is limited by some disadvantages: i) very low number in the adult tissues, ii) low proliferative rate, and iii) invasive procedures needed to obtain them, which can lead to morbidity for the donors.

Hence, embryo-derived tissues, such as placenta (7), amniotic fluid (8), umbilical cord (UC) blood (9) and UC itself (10), could represent the best source of stem cells. Since all these tissue are discarded after birth, the harvesting of stem cells is a procedure non-invasive and safe for both mother and child. In particular, it has been supposed that fetal-derived stem cells, which are very numerous in fetal blood during the first trimester of pregnancy (11), could leave the blood stream and localize into the UC. Abundant experimental evidence has been accumulated that UC contains mesenchymal-like stem cells. It has been demonstrated that UC cells obtained from the sub-endothelial layer of umbilical vein are able to differentiate in vitro into adipocytes and osteoblasts $(12,13)$. Mesenchymal-like stem cells have been also recovered from Wharton's jelly, the gelatinous connective tissue of UC, and differentiated in vitro into adipocytes, chondrocytes, osteocytes (10) and neurons (14). Moreover, findings are available that $\mathrm{UC}$ cells are able to regenerate in vivo dopaminergic neurons in an animal model of Parkinson's disease (15).

In this study, we provide the first demonstration that CD105(+) cells obtained from Wharton's jelly can undergo differentiation towards skeletal muscle cells both in vitro by 
inductive media and in vivo in a rat model of chemicallyinduced muscle damage.

\section{Materials and methods}

Animals and reagents. Lewis male rats, weighing from 250 to $320 \mathrm{~g}$, were purchased from Charles-River (Como, Italy) and maintained on a 12-h dark-light cycle, with free access to laboratory chow and tap water. The experiment protocol was approved by the local Ethics Committee for Biomedical Studies. Bupivacaine chloridrate (Marcaine) was provided by AstraZeneca (Milan, Italy), and matrigel by Becton Dickinson Labware (Bedford, MA). Tiletamine and zolazepam chloridrate (zoletil) were obtained from Laboratories Virbac (Carros, France), and xilazine chloridrate (rompun) and enrofloxacin (Baytril) from Bayer AG (Leverkusen, Germany). Fetal bovine serum (FBS), horse serum (HS), Dulbecco's modified Eagle's medium (DMEM) low glucose, $\alpha$-minimun essential medium $(\alpha-M E M)$, Trizol reagent, sense and antisense primers, ethidium bromide, DEPC water and 450 Tosylactivated Dynabeads were provided by Invitrogen Life Technologies (Carlsbad, CA). FBS specific for mesenchymal stem cells was purchased from Stem Cell Technologies (Vancouver, Canada), and chick embryo extract (CEE) from ICN Biomedicals (Irvine, CA). Polyclonal antibodies against CD105, CD90, CD31, KDR, CD34, CD38, CD45, CD54, serum response element binding protein (SREBP)-1, human leukocyte antigen (HLA)1, polyomavirus enhancer binding protein (PEBP) $2 \alpha \mathrm{A}$, myogenic factor (Myf) 5 and myoblast determination protein-1 (MyoD), and antibodies against von Willebrand factor (vWf) and smooth muscle actin (SMA) from Dako (Glostrup, Denmark). ABC kit, Peroxidase substrate kit $\mathrm{DAB}$, fluorescent avidin kit and mounting medium for fluorescence with 4',6-diamidino-2-phenylindole (DAPI) were purchased from Vector Laboratories (Burlingame, CA). dNTPs mix, random hexamers, RNase inhibitor, multiscribe reverse transcriptase and Ampli Taq Gold were obtained from Applied Biosystems (Foster City, CA). DNA-Free kit was provided by Ambion (Pero, Italy). DMEM high glucose, phosphate buffered saline (PBS), antibiotic-antimicotic solution $(10000 \mathrm{U} / \mathrm{ml}$ penicillin, $\mu \mathrm{g} / \mathrm{ml}$ streptomycin sulphate and $\mu \mathrm{g} / \mathrm{ml}$ amphotericin B), monoclonal antibody against sarcomeric tropomyosine, and all other chemicals and reagents were provided by Sigma-Aldrich Corp. (St. Louis, MO).

Cell cultures. Twenty-seven human UCs were obtained, with the mother's consent, from full-term caesarean deliveries and processed within $24 \mathrm{~h}$. After washing with PBS, the umbilical vessels were manually removed and the jelly was minced into small fragments which were put into $100-\mathrm{mm}$ petri dishes and cultured with the proliferative medium composed of DMEM low glucose, supplemented with $2 \mathrm{mM}$ L-glutamine, $1 \%$ antibiotic-antimycotic solution and $20 \%$ FBS specific for mesenchymal stem cell cultures. In order to allow the cells to migrate from the tissue fragments, the medium was removed only after 5-7 days and thereafter changed twice a week. The cultures were observed daily by a phase-contrast microscope. At $\sim 70-80 \%$ confluence, the cells were detached using trypsin $(0.25 \% \mathrm{w} / \mathrm{v})$ and $\operatorname{EDTA}(0.02 \% \mathrm{w} / \mathrm{v})$ in PBS $(1: 1 \mathrm{v} / \mathrm{v})$. Primary cultures grown to near-confluence were exposed to immunoseparation using M-450 tosylactivated dinabeads coated with anti-CD105, -CD31 or -KDR antibodies. Cells $\left(10^{6} / \mathrm{ml}\right)$ were added to coated beads (five beads per cell), incubated for $30 \mathrm{~min}$ at $4^{\circ} \mathrm{C}$, washed several times in PBS and then resuspended in the proliferative medium. Thus, cultures expressing CD105 and lacking CD31 and KDR were obtained by positive and negative immunoseparation.

Population doubling. CD105(+)/CD31(-)/KDR(-) (9x10³ cells/ $\mathrm{cm}^{2}$ ) were seeded on 100-mm petri dishes, cultured for 3 days, detached and counted by trypan blue exclusion. This procedure was repeated until the 16th passage and doubling population was calculated as the ratio between the $\log _{10}(\mathrm{Nh})-\log _{10}(\mathrm{Ni})$ and $\log _{10}(2)$, where Ni was the number of seeded cells and $\mathrm{Nh}$ the number of harvested cells. The cumulative population doubling level was calculated by adding the population doubling for each passage to the population doubling level of the previous passage.

Induction of adipogenic, osteogenic and myogenic differentiation. $\mathrm{CD} 105(+) / \mathrm{CD} 31(-) / \mathrm{KDR}(-)$ cells $\left(5 \times 10^{3}\right.$ cells $\left./ \mathrm{cm}^{2}\right)$ were seeded on each well of 8 -well chamber slides and cultured in the proliferative medium for 4 days. Then, osteogenic and adipogenic differentiative media were added and changed twice a week. Adipogenic differentiation medium was composed of DMEM low glucose supplemented with $10 \%$ FBS, $1 \%$ antibiotic-antimicotic solution, $1 \mu \mathrm{M}$ dexamethasone, $0.5 \mathrm{mM}$ 3-isobutyl-1-methylxanthine, $10 \mu \mathrm{g} /$ $\mathrm{ml}$ insulin and $60 \mu \mathrm{M}$ indomethacin. Osteogenic differentiation medium contained $\alpha$-MEM, supplemented, with $10 \%$ FBS, $1 \%$ antibiotic-antimicotic solution, $0.1 \mu \mathrm{M}$ dexamethasone, $10 \mathrm{mM}$ $\beta$-glycerophosphate and $0.05 \mathrm{mM} 2$-phosphate ascorbic acid. To induce myogenic differentiation, cells were seeded on 8-well chamber slides previously coated with 1:10-diluted matrigel and grown in the proliferative medium, as described above. Myogenic inductive medium was composed of DMEM high glucose, supplemented with $20 \%$ FBS, $1 \%$ antibioticantimicotic solution, and $10 \mu \mathrm{M} 5$-azacytidine. After $48 \mathrm{~h}$, myogenic proliferative medium (DMEM high glucose, $20 \%$ FBS, $1 \%$ antibiotic-antimicotic solution, $10 \% \mathrm{HS}$, and $1 \%$ CEE) was added. As negative control, some cells were cultured in the proliferative medium deprived of differentiation factors.

Immunocytochemistry. Staining was performed on both primary UC cells and CD105(+)/CD31(-)/KDR(-) cells before and after induction of differentiation. Cells were grown on glass chamber slides, as detailed above. At various time points, the cultures were fixed with $4 \%$ paraformaldehyde for $30 \mathrm{~min}$ and washed in PBS. Immunocytochemical staining was localized either with peroxidase or with immunofluorescence using the $\mathrm{ABC}$ kit and the fluorescent avidin kit, respectively. Endogenous peroxidases were inactivated with a $30 \%$ hydrogen peroxide solution at dark for $40 \mathrm{~min}$, and aspecific reactions were avoided using a blocking solution, containing $10 \%$ serum obtained from the same species where the secondary antibody was raised. Then, the samples were incubated overnight with the following anti-human primary antibodies (1:500 dilution): CD105, CD90, CD31, KDR, CD34, CD38, CD45, CD54, SREBP, PEBS2 $\alpha$ A, Myf5, MyoD, vWf and SMA. After rinsing with PBS, cells were incubated 

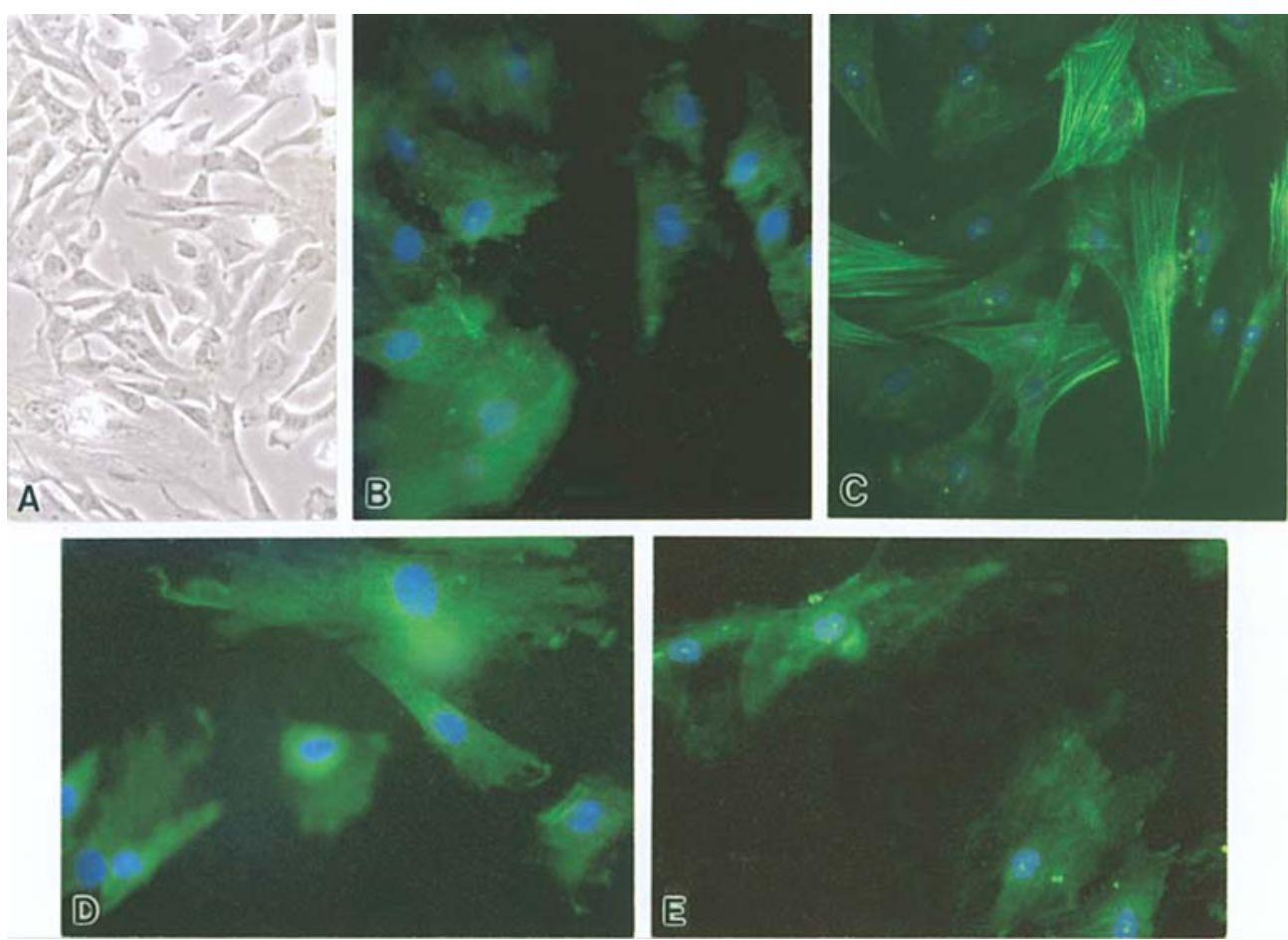

Figure 1. Characteristics of primary cultures obtained from Wharton's jelly. Phase-contrast microscopy of cells 20 days after the explant (A). Immunofluorescence staining of CD105 (B), SMA (C), KDR (D), and vWf (E) in primary cultures. Magnification: A, x100; B-E, x400.
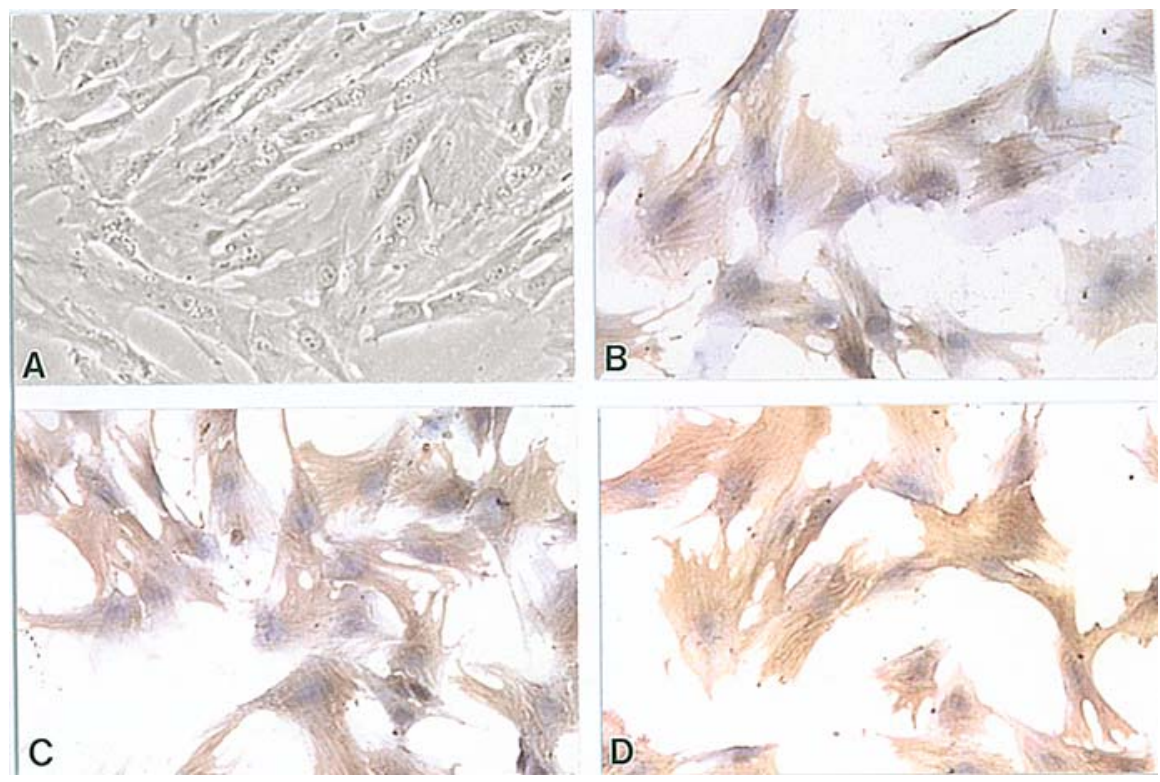

Figure 2. Characteristics of CD105(+)/CD31(-)/KDR(-) cells obtained by immunoseparation. Phase-contrast microscopy (A), and immunocytochemical staining of CD105 (B), CD90 (C), and SMA (D). Magnification: A, x100; B-D, x400.

with biotin-labeled panspecific secondary antibody. For immunoperoxidase detection, the antigen was localized with $\mathrm{DAB}$ and hydrogen peroxide. Nuclei were counterstained with hematoxylin. Alternatively, after incubation with the secondary antibody, fluorescein avidin kit was used, and antibody binding was visualized as a green fluorescent signal. Nuclei were counterstained with DAPI. Negative controls were carried out by omitting the primary antibody (16).
Cytochemical staining. Cells cultured in the adipogenic medium for 7 days were fixed in acetone for $10 \mathrm{~min}$, then hydrated with distilled water, and stained for $15 \mathrm{~min}$ in $0.5 \%$ Oil Red O isopropanol solution. Nuclei were counterstained with hematoxylin. Cells cultured in the osteogenic medium for 7 and 9 days were fixed in $4 \%$ paraformaldehyde for $30 \mathrm{~min}$ and washed with PBS. The cultures were then treated with $1 \%$ silver nitrate solution and exposed to UV light for 


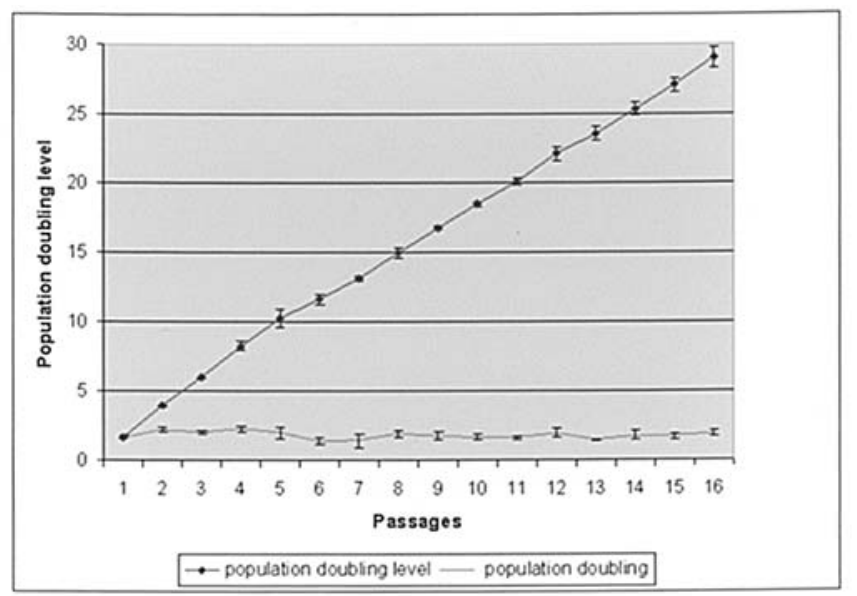

Figure 3. Population doubling and cumulative population doubling level of cultured CD105(+)/CD31(-), KDR(-) cells. Each point represent the mean $\pm \mathrm{SD}$ of three separate experiments.

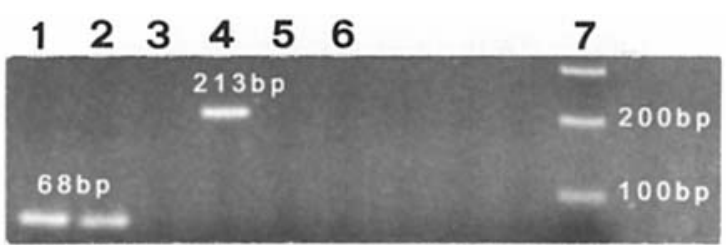

Figure 4. Ethidium bromide-stained $2 \%$ agarose gel showing cDNA samples amplified with GAPDH (lanes 1 and 2) and Sry specific primers from RNA of CD105(+)/CD31(-)/KDR(-) cells obtained from Wharton's jelly of a newborn male (lane 4) and two newborn females (lanes 5 and 6). Lane 7 was loaded with $200 \mathrm{ng}$ of a size marker (100 bp ladder Abgene). No amplification with water instead of RNA is shown as a negative control (lane 3).

$45 \mathrm{~min}$. Thereafter, samples were incubated in $3 \%$ sodium tiosulphate and counterstained with $0.2 \%$ safranin O. Cells cultured in the proliferative medium were taken as negative controls.

Reverse transcription (RT)-polymerase chain reaction $(P C R)$. Total mRNA was extracted from CD105(+)/CD31(-)/KDR(-) cells using TRIzol reagent (17), and transcribed using MultiScribe RT and random hexamers as primers for the first strand cDNA synthesis (18). The amplification of the resulting cDNA was carried out using specific primers, as described earlier $(19,20)$. Briefly, in a thermal cycler (I-Cycler; BioRad, Milan, Italy), after an initial denaturation step at $95^{\circ} \mathrm{C}$ for $10 \mathrm{~min}$, we used a denaturation step at $95^{\circ} \mathrm{C}$ for $30 \mathrm{sec}$, an annealing step at $60^{\circ} \mathrm{C}$ for $45 \mathrm{sec}$, and an extension step at $72^{\circ} \mathrm{C}$ for $45 \mathrm{sec}$ for a total of 40 cycles. To rule out the possibility of amplifying genomic DNA, RNA samples were treated with the DNA-free kit. Detection of the PCR amplification products was performed by size fractionation on $2 \%$ agarose gel electrophoresis. As a positive control, amplification of the human glyceraldehyde 3-phosphate dehydrogenase (GAPDH) RNA was performed. Primer sequences and predicted sizes of amplicons are: 1) Sry: sense 5'-TCGCACTCTCCTTGTTTTTG-3', antisense 5'-TGGGTC GCTTCACTCTATCC-3' (213 bp); 2) GAPDH: sense, 5'-AGT CCCTGCCACACTCAGTC-3' and antisense, 5'-AGGGGTC TACATGGCAACTG-3' (68 bp).

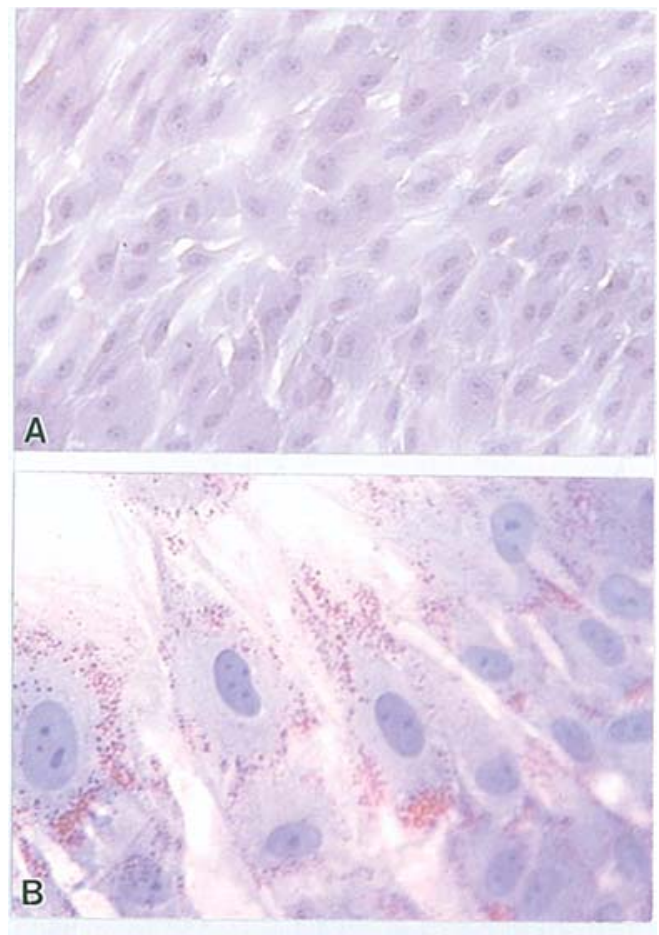

Figure 5. Adipogenic differentiation of CD105(+)/CD31(-)/KDR(-) cells. Oil red $\mathrm{O}$ staining of cultures grown in proliferative medium (controls) (A) or adipogenic medium for 7 days (B). Magnification: A, x100; B, x400.

In vivo studies. Twelve Lewis rats were anesthetized with zoletil $(35 \mathrm{mg} / \mathrm{kg}$ ) and rompun $(2 \mathrm{mg} / \mathrm{kg})$, and their tibialis anterior muscle was exposed. A narrow gauge $(27 \mathrm{G})$ was inserted into each of the ends and in the middle of the muscle, and $0.5 \mathrm{ml}$ of $0.5 \%(\mathrm{w} / \mathrm{v})$ bupivacaine hydrochloride solution were injected, as described by Hill et al (21). Animals were treated with antibiotics (Baytril, $0.2 \mathrm{ml} / \mathrm{kg}$ ) for 2 day. Fortyeight hours after the bupivacaine injection, $0.5 \mathrm{ml}$ sterile phosphate buffer saline, containing $(n=6)$ or not $(n=6) 10^{6}$ CD105(+)/CD31(-)/KDR(-) cells, were injected in to the muscle, using the same procedure described above. No immunosuppressive therapy was carried out. After 7 and 14 days, the animals were sacrificed and their tibialis anterior muscle was removed, fixed in $10 \%$ formaldehyde and embedded in paraffin. Paraffin sections (5-7 $\mu \mathrm{m}$ in thickness) were obtained and stained with haematoxylin and eosin. Immunofluorescence was also performed as described above, using antibodies against human HLA 1 and sarcomeric tropomyosine (1:1000 dilution).

\section{Results}

At 12 days from explants, spindle-shape cells started to migrate out from Wharton's Jelly fragments and completely covered the growth area within 17-20 days (Fig. 1A). Immunocytochemical analysis showed that UC cells were negative for hematopoietic lineage markers (CD34, CD38, CD45 and CD54) and differentiated cells (SREBP, PEBS2 $\alpha$ A and Myf5). On the contrary, they expressed mesenchymal markers, such as CD105 (Fig. 1B) and CD90, SMA (Fig. 1C), and HLA 1 antigen. Moreover, immunoreactivity was detected for KDR (Fig. 1D) and vWf (Fig. 1E), but not for CD31. 

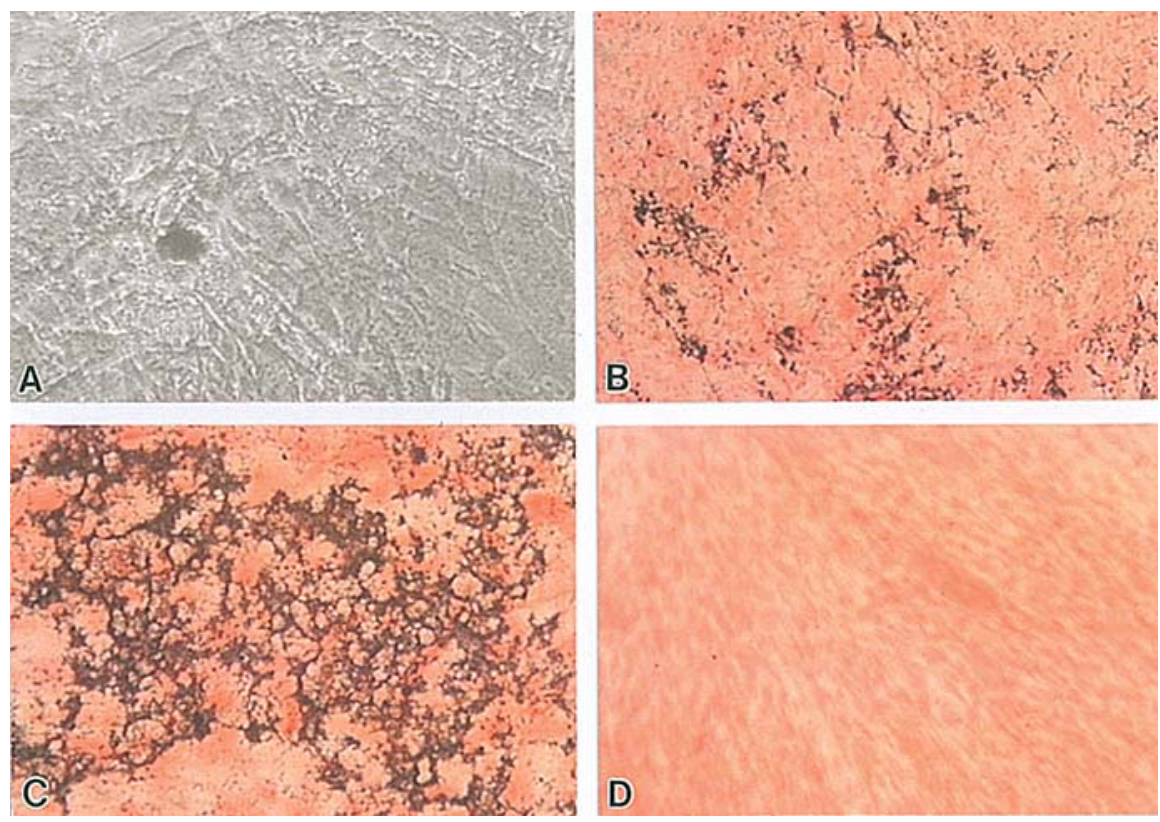

Figure 6. Osteogenic differentiation of CD105+/CD31(-)/KDR(-) cells. Phase contrast microscopy of cultures grown in inductive medium for 7 days (A). Von Kossa staining of cells cultured in inductive medium for 7 (B) and 9 days (C) or in proliferative medium for 9 days (D). Magnification: A-D, x100.

To enrich the cultures with mesenchymal cells and eliminate endothelial cells or their progenitor, CD105(+)/ CD31(-)/KDR(-) cells were purified by immunoseparation. Also these cells showed a fibroblast-like shape (Fig. 2A), and their immunoreactivity (Fig. 2B-D) was the same as that observed in primary cultures, except for the lack of KDR and vWf antigens. CD105(+)/CD31(-)/KDR(-) cells were cultured until the 16 th passage, reaching $\sim 30$ population doublings (Fig. 3).

To verify the presence of the fetal cells in these cultures, RT-PCR was performed to identify Sry (sex determining region $\mathrm{Y}$ gene) mRNA. Total mRNA was extracted from CD105(+)/CD31(-)/KDR(-) cells derived from UC of male children. All these samples expressed Sry mRNA. No amplification of the gene was present in those obtained from female children used as controls (Fig. 4).

UC immunoseparated cells were cultured in inductive media to evaluate their potential to differentiate into osteoblasts, adipocytes and myoblasts. At 7 days of adipogenic induction, cells began to show a round shape and most of them contained cytoplasmatic vacuoles which were positive to Oil Red O staining. Control cells grown with proliferative medium were negative to the above mentioned staining procedure (Fig. 5A and B). After 7 days of osteogenic induction, the cells started to stratify (Fig. 6A) and to produce mineralized matrix, as revealed by von Kossa staining (Fig. 6B). Both stratification and calcium salt deposition increased until day 9 (Fig. 6C) and were absent in control cultures (Fig. 6D). After 7 and 14 days of myogenic induction, the cells presented an elongated shape and started to fuse into multinucleated elements (Fig. 7A). Myf5 was expressed from day 7 (Fig. 7B) to day 16, whereas MyoD-immunoreactivity was detected from day 11. At day 16 most multinucleated cells were positive to Myo-D (Fig. 7C).

To evaluate in vivo the differentiation potential of CD105(+)/CD31(-)/KDR(-) cells into myogenic lineage, the
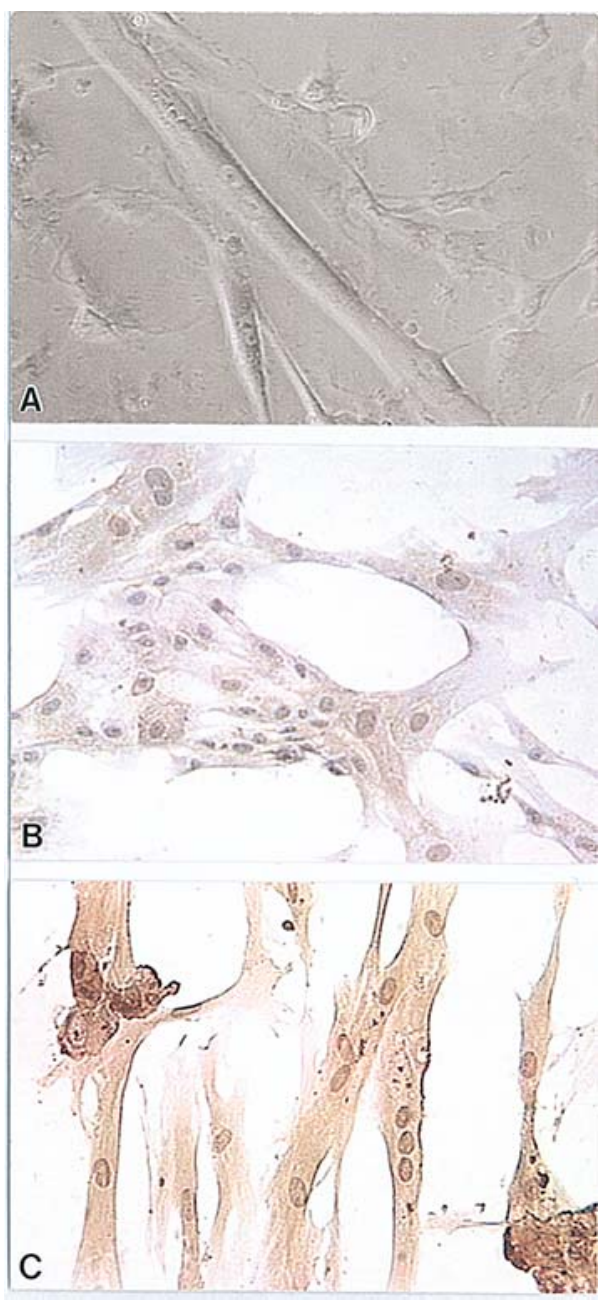

Figure 7. Myogenic differentiation of CD105(+)/CD31(-)/KDR(-) cells. Phase contrast microscopy of cultures grown in inductive medium for 14 days (A). Expression of Myf5 in cells cultured in myogenic medium for 7 days (B). Immunocytochemistry staining of MyoD in cells cultured in inductive medium for 16 days (C). Magnification: A-C, x100. 

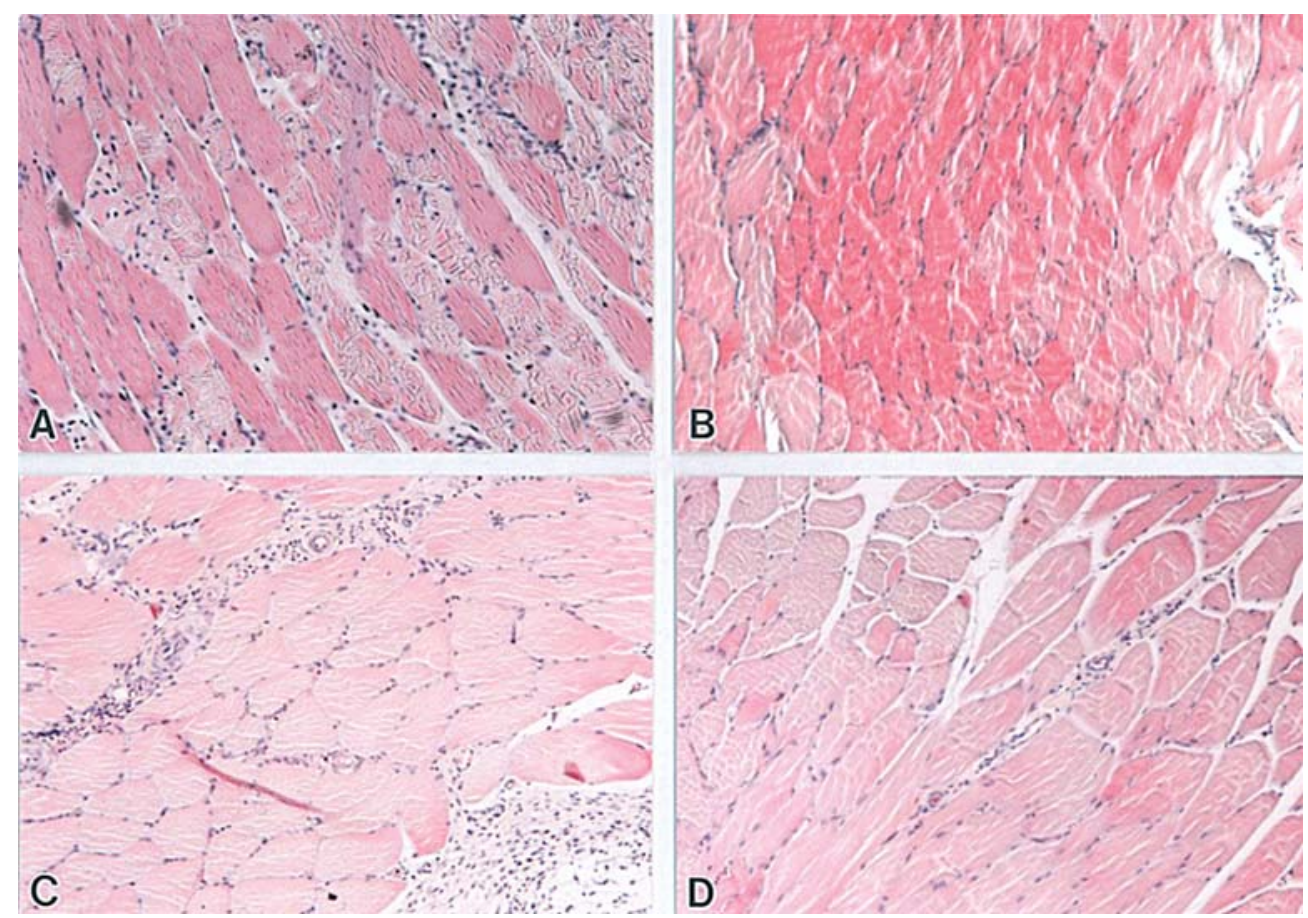

Figure 8. Haematoxylin and eosin-stained paraffin sections of the tibialis anterior muscle, $48 \mathrm{~h}$ after bupivacaine treatment (A), 7 days after the injection of saline buffer (B), and 7 (C) or 14 days (D) after the injection of CD105(+)/CD31(-)/KDR(-) cell suspension. Magnification: A-D, x100
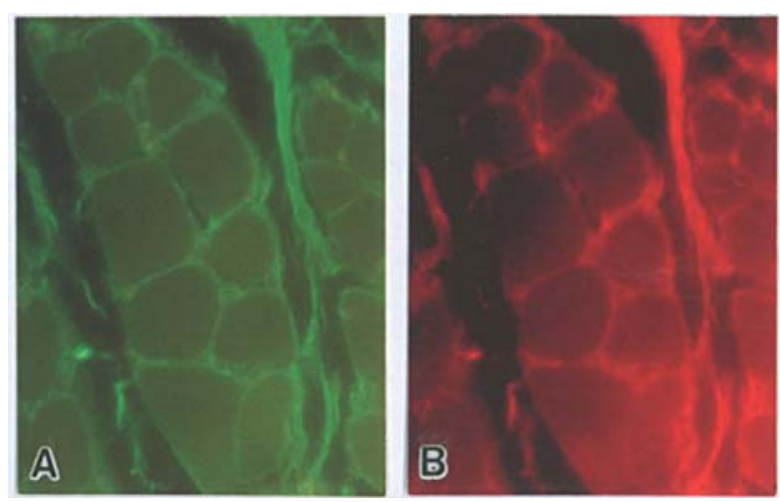

Figure 9. Double immunofluorescence of tibialis anterior muscle sections, 14 days after the injection of CD105(+)/CD31(-)/KDR(-) cell suspension: expression of HLA 1 (A) and sarcomeric tropomyosine (B). Magnification: $\mathrm{A}$ and $\mathrm{B}, \mathrm{x} 400$.

cells were injected in the rat tibialis anterior muscle previously damaged with bupivacaine chloridrate. Two days after the treatment with this myotoxic drug (Fig. 8A), a severe inflammatory response and large necrotic areas were observed inside the muscle. At this time UC cells or saline buffer (control) were injected. Seven days after cell transplantation, necrotic areas disappeared in both control (Fig. 8B) and treated animals (Fig. 8C). Nevertheless, animals that received UC cells showed mild signs of flogosis, which decreased at day 14 (Fig. 8D). Transplanted cells were present in the muscle until day 14, as revealed by immunoreactivity to HLA 1 (Fig. 9A). Moreover, the same cells co-expressed sarcomeric tropomyosine (Fig. 9B).

\section{Discussion}

In recent years, mesenchymal cells have been obtained from both subendothelial layer of human umbilical vein $(12,13)$ and Wharton's jelly. These latter cells displayed a high proliferative rate (22) and were able to differentiate into adipocytes, osteoblasts, condrocytes (23), cardiomyocytes (10), neurons, and glia (14). However, it has not been demonstrated whether the cells derived from Wharton's jelly are able to give rise in vitro and in vivo to skeletal muscle cells.

In this study, primary cultures were composed of myofibroblast-like spindle-shape cells positive to anti-SMA antibodies, which characterize human UC cells at various steps of pregnancy (24). No markers of hematopoietic lineage were present, as demonstrated by the lack of immunoreactivity towards anti-CD34 (25), -CD38 (26), -CD40 (27), and -CD45 antibodies (28). Moreover, primary cultures did not contain mesenchymal-derived differentiated cells, as revealed by immunocytochemistry carried out to detect adipocytes, osteoblasts, myoblasts and fully differentiated endothelial cells using anti-SREB, -PEBS2 $\alpha$ A, -Myf5, and -CD31 antibodies, respectively. However, several cell types were positive to antivWf (29) and anti-KDR (30) antibodies, suggesting the presence of endothelial cell progenitors (31). These observations agree with those of Panepucci et al (32), which pointed out that UC cells are, at least in part, committed to endothelial differentiation. Nevertheless, most cells presented the surface antigens CD90 and CD105, which are also expressed on the bone marrow mesenchymal stem cells $(32,33)$.

Hence, it seemed of great relevance to obtain cultures exclusively composed of cells expressing mesenchymal 
markers and not already committed towards specific differentiation pathways. Thus, by means of positive and negative immunoseparation, cells expressing CD105, but not KDR and CD31 antigens were selected. Although primary cultures were negative to CD31, a negative immunoseparation was carried out to avoid the presence of fully differentiated endothelial cells that may have been formed during the culture period. CD105(+)/CD31(-)/KDR(-) cells were characterized by an elongated shape and good proliferation rates. After 16 serial passages, no variation in cell morphology or senescence signs were observed.

The increasing interest in UC as an alternative source of stem cells derives from its embryonic origin, suggesting the presence of fetal cells characterized by a high proliferative rate. Moreover, since in the first period of pregnancy UC blood contains mesenchymal progenitors, whose number decreases in the last months, it has been supposed that these cells could localize in UC (13). In keeping with this hypothesis, our data demonstrated that CD105(+)/CD31(-)/ KDR(-) cultures obtained from male children contain Sry mRNA. The RT-PCR of Sry gene (Yp11.3) (34) represents a sensitive and specific technique for detecting male DNA in a mixed cell population (35).

CD105(+)/CD31(-)/KDR(-) cells were able to differentiate in vitro into adipocytes, osteoblasts and myoblast-like cells. According to earlier studies (23), after 7 days of adipogenic induction, several lipid vacuoles, whose number and dimension increase at day 14, can be seen in the cytoplasm. Osteoblast differentiation was revealed by cell stratification and deposition of mineralized extracellular matrix. CD105(+)/CD31(-)/KDR(-) cells were found to differentiate in vitro into myoblast-like cells, expressing Myf5 and MyoD after 7 and 11 days of myogenic induction, respectively. Both Myf5 and MyoD belong to the myogenic regulatory factor (MRF) family, which is composed of bHLH (basic Helix-Loop-Helix) proteins promoting the transcription of genes involved in the muscle development (36). After myogenic induction, MRF proteins are expressed in vitro by ESCs in a time-dependent manner, resembling that observed in vivo during the development of mouse embryos (37). The timing of expression of Myf5 and MyoD in CD105(+)/CD31(-)/KDR(-) cells is similar to that described during embryonic development and in myoblast cultures.

To verify whether UC cells could differentiate also in vivo towards the myogenic lineage and play a role in skeletal muscle regeneration, an animal model of chemically-induced muscle damage has been used. The local injection of bupivacaine quickly leads to the destruction of skeletal muscle fibres because it damages mitochondria (38), cytoplasmic membrane, and sarcoplasmatic reticulum (39). However, this drug does not affect muscle satellite cells which are activated, thus allowing tissue repair (40). This model of muscle damage is often used to study muscle regeneration induced by biologically active compounds or stem cell transplants $(21,41)$.

In our study, CD105(+)/CD31(-)/KDR(-) cell suspensions have been injected after $48 \mathrm{~h}$ from bupivacaine treatment because at this time we observed the highest degree of muscle damage. At two weeks from cell transplantation, skeletal muscle appears completely repaired, as occurred in control rats treated with saline buffer. Although immuno- suppresive therapy has not been used, at one week we observed only a moderate inflammatory response, which decreased at two weeks. Moreover, transplanted cells are present in the muscle for two weeks and differentiate into skeletal muscle cells, as demonstrated by the co-localization of HLA 1 and sarcomeric tropomyosine antigens. This result suggests that CD105(+)/CD31(-)/KDR(-) cells are able not only to differentiate in vivo towards the myogenic lineage, but also to contribute to the muscle regenerative process. Our findings agree with those of Weiss et al (15) and Medicetty et al (42), who demonstrated that cells obtained from Wharton's jelly do not elicit rejection response and can proliferate and express tyroxinehydroxylase, when transplanted into the brain of rats previously treated with 6-hydroxydopamine.

Taken together, our results indicate that Wharton's jelly contains a cell population, at least in part of fetal origin, characterized in vitro by a good proliferation rate and plasticity, and in vivo by the ability to differentiate towards the myogenic lineage. Further studies must be carried out to better characterize this population and to verify whether it could also differentiate into endodermic- and ectodermicderived cells.

\section{Acknowledgements}

This work was supported by a grant from the Italian Ministry of University and Research (FIRB 2001) to G.G.N. and P.P.P.

\section{References}

1. Gadue P, Huber TL, Nostro MC, Kattman S and Keller GM: Germ layer induction from embryonic stem cells. Exp Hematol 33: 955-964, 2005.

2. Hug K: Sources of human embryos for stem cell research: ethical problems and their possible solutions. Medicina (Kaunas) 41: 1002-1010, 2005.

3. Jensen UB, Lowell S and Watt FM: The spatial relationship between stem cells and their progeny in the basal layer of human epidermis: a new view based on whole-mount labelling and lineage analysis. Development 126: 2409-2418, 1999.

4. Slack JM: Stem cells in epithelial tissues. Science 287: 1431-1433, 2000

5. Gage FH: Mammalian neural stem cells. Science 287: 1433-1438, 2000.

6. Kemp KC, Hows J and Donaldson C: Bone marrow-derived mesenchymal stem cells. Leuk Lymphoma 46: 1531-1544, 2005.

7. Portmann-Lanz CB, Schoeberlein A, Huber A, Saeger R, Malek A, Holzgreve W and Surbek DV: Placental mesenchymal stem cells as potential autologous graft for pre- and perinatal neuroregeneration. Am J Obstet Gynecol 194: 664-673, 2006.

8. In't Anker PS, Scherjon SA, Kleijburg-van der Keur C, Noort WA, Claas FH, Willemze R, Fibbe WE and Kanhai HH: Amniotic fluid as a novel source of mesenchymal stem cells for therapeutic transplantation. Blood 102: 1548-1549, 2003.

9. Erices A, Conget P and Minguell JJ: Mesenchymal progenitor cells in human umbilical cord blood. Br J Haematol 109: 235-242, 2000.

10. Wang HS, Hung SC, Peng ST, Huang CC, Wei HM, Guo YJ, Fu YS, Lai MC and Chen CC: Mesenchymal stem cells in the Wharton's jelly of the human umbilical cord. Stem Cells 22: 1330-1337, 2004.

11. Campagnoli C, Roberts IA, Kumar S, Bennett PR, Bellantuono I and Fisk NM: Identification of mesenchymal stem/progenitor cells in human first-trimester fetal blood, liver, and bone marrow. Blood 98: 2396-2402, 2001.

12. Covas DT, Siufi JL, Silva AR and Orellana MD: Isolation and culture of umbilical vein mesenchymal stem cells. Braz J Med Biol Res 36: 1179-1183, 2003. 
13. Romanov YA, Svintsitskaya VA and Smirnov VN: Searching for alternative sources of postnatal human mesenchymal stem cells: candidate MSC-like cells from umbilical cord. Stem Cells 21: 105-110, 2003.

14. Mitchell KE, Weiss ML, Mitchell BM, Martin P, Davis D, Morales L, Helwig B, Beerenstrauch M, Abou-Easa K, Hildreth T, Troyer D and Medicetty S: Matrix cells from Wharton's jelly form neurons and glia. Stem Cells 21: 50-60, 2003.

15. Weiss ML, Medicetty S, Bledsoe AR, Rachakatla RS, Choi M, Merchav S, Luo Y, Rao MS, Velagaleti G and Troyer D: Human umbilical cord matrix stem cells: preliminary characterization and effect of transplantation in a rodent model of Parkinson's disease. Stem Cells 24: 781-792, 2005

16. Belloni AS, Guidolin D, Salmaso R, Bova S, Rossi GP and Nussdorfer GG: Adrenomedullin, ANP and BNP are colocalized in a subset of endocrine cells in the rat heart. Int J Mol Med 15: 567-571, 2005.

17. Andreis PG, Rucinski M, Neri G, Conconi MT, Petrelli L, Parnigotto PP, Malendowicz LK and Nussdorfer GG: Neuropeptides $\mathrm{B}$ and $\mathrm{W}$ enhance the growth of human adrenocortical carcinoma-derived NCI-H295 cells by exerting MAPK p42/p44mediated proliferogenic and antiapoptotic effects. Int J Mol Med 16: 1021-1028, 2005.

18. Albertin G, Carraro G, Petrelli L, Guidolin D, Neri G and Nussdorfer GG: Endothelin-1 and adrenomedullin enhance the growth of human adrenocortical carcinoma-derived SW-13 cell line by stimulating proliferation and inhibiting apoptosis. Int $\mathrm{J}$ Mol Med 15: 469-474, 2005.

19. Albertin G, Carraro G and Nussdorfer GG: Human adrenomedullin gene silencing by short interfering RNAs: a preliminary study. Int J Mol Med 15: 579-583, 2005.

20. Rucinski M, Andreis PG, Ziolkowska A, Nussdorfer GG and Malendowicz LK: Differential expression and function of beacon in the rat adrenal cortex and medulla. Int J Mol Med 16: 35-40, 2005.

21. Hill $\mathrm{M}$ and Goldspink G: Expression and splicing of the insulinlike growth factor gene in rodent muscle is associated with muscle satellite (stem) cell activation following local tissue damage. J Physiol (Lond) 549: 409-418, 2003.

22. Sarugaser R, Lickorish D, Baksh D, Hosseini MM and Davies JE: Human umbilical cord perivascular (HUCPV) cells: a source of mesenchymal progenitors. Stem Cells 23: 220-229, 2005.

23. Kim JW, Kim SY, Park SY, Kim YM, Kim JM, Lee MH and Ryu HM: Mesenchymal progenitor cells in the human umbilical cord. Ann Hematol 83: 733-738, 2004.

24. Kobayashi K, Kubota T and Aso T: Study on myofibroblast differentiation in the stromal cells of Wharton's jelly: expression and localization of alpha-smooth muscle actin. Early Hum Dev 51: 223-233, 1998 .

25. Fackler MJ, Krause DS, Smith OM, Civin CI and May WS: Full-length but not truncated CD34 inhibits hematopoietic cell differentiation of M1 cells. Blood 85: 3040-3047, 1995.

26. Mehta K, Shahid U and Malavasi F: Human CD38, a cellsurface protein with multiple functions. FASEB J 10: 1408-1417, 1996.

27. Gordon J: CD40 and its ligand: central players in B lymphocyte survival, growth, and differentiation. Blood Rev 9: 53-56, 1995.
28. Trowbridge IS and Thomas ML: CD45: an emerging role as a protein tyrosine phosphatase required for lymphocyte activation and development. Annu Rev Immunol 12: 85-116, 1994.

29. Rosnoblet C, Ribba AS, Wollheim CB, Kruithof EK and Vischer UM: Regulated von Willebrand factor (vWf) secretion is restored by pro- $\mathrm{vWf}$ expression in a transfectable endothelial cell line. Biochim Biophys Acta 1495: 112-119, 2000.

30. Peichev M, Naiyer AJ, Pereira D, Zhu Z, Lane WJ, Williams M, Oz MC, Hicklin DJ, Witte L, Moore MA and Rafii S: Expression of VEGFR-2 and AC133 by circulating human CD34(+) cells identifies a population of functional endothelial precursors. Blood 95: 952-958, 2000

31. Hristov M and Weber C: Endothelial progenitor cells: characterization, pathophysiology, and possible clinical relevance. J Cell Mol Med 8: 498-508, 2004

32. Panepucci RA, Siufi JL, Silva WA Jr, Proto-Siquiera R, Neder L, Orellana M, Rocha V, Covas DT and Zago MA: Comparison of gene expression of umbilical cord vein and bone marrow-derived mesenchymal stem cells. Stem Cells 22: 1263-1278, 2004.

33. Tsukamoto AS, Reading C, Carella A, Frassoni F, Gorin C, LaPorte J, Negrin R, Blume K, Cunningham I and Deisseroth A: Biological characterization of stem cell present in mobilized peripheral blood of CML patients. Bone Marrow Transplant 14 (Suppl 3): S25-S32, 1994.

34. An J, Beauchemin N, Albanese J, Abney TO and Sullivan AK: Use of a rat cDNA probe specific for the Y chromosome to detect male-derived cells. J Androl 18: 289-293, 1997.

35. Muller-Ehmsen J, Whittaker P, Kloner RA, Dow JS, Sakoda T, Long TI, Laird PW and Kedes L: Survival and development of neonatal rat cardiomyocytes transplanted into adult myocardium. J Mol Cell Cardiol 34: 107-116, 2002.

36. Winter B, Braun T and Arnold HH: Co-operativity of functional domains in the muscle-specific transcription factor Myf-5. EMBO J 11: 1843-1855, 1992.

37. Rohwedel J, Maltsev V, Bober E, Arnold HH, Hescheler J and Wobus AM: Muscle cell differentiation of embryonic stem cells reflects myogenesis in vivo: developmentally regulated expression of myogenic determination genes and functional expression of ionic currents. Dev Biol 164: 87-101, 1994.

38. Hall-Craggs EC: Early ultrastructural changes in skeletal muscle exposed to the local anaesthetic bupivacaine (Marcaine). Br J Exp Pathol 61: 139-149, 1980.

39. Nonaka I, Takagi A, Ishiura S, Nakase H and Sugita H: Pathophysiology of muscle fiber necrosis induced by bupivacaine hydrochloride (Marcaine). Acta Neuropathol (Berl) 60: 167-174, 1983.

40. Nishizawa T, Tamaki H, Kasuga N and Takekura H: Degeneration and regeneration of neuromuscular junction architecture in rat skeletal muscle fibers damaged by bupivacaine hydrochloride. $\mathrm{J}$ Muscle Res Cell Motil 24: 527-537, 2003.

41. Pette D, Sketelj J, Skorjanc D, Leisner E, Traub I and Bajrovic F: Partial fast-to-slow conversion of regenerating rat fast-twitch muscle by chronic low-frequency stimulation. J Muscle Res Cell Motil 23: 215-221, 2002.

42. Medicetty S, Bledsoe AR, Fahrenholtz CB, Troyer D and Weiss ML: Transplantation of pig stem cells into rat brain: proliferation during the first 8 weeks. Exp Neurol 190: 32-41, 2004. 